Technological University Dublin

ARROW@TU Dublin

\title{
Effect of High- and Low-Molecular-Weight Hyaluronic-Acid- Functionalized-AZ31 Mg and Ti Alloys on Proliferation and Differentiation of Osteoblast Cells
}

\author{
Sankalp Agarwal \\ Technological University Dublin, sankalp.agarwal@tudublin.ie \\ Brendan Duffy \\ Technological University Dublin, brendan.duffy@tudublin.ie \\ James Curtin \\ Technological University Dublin, james.curtin@tudublin.ie
}

See next page for additional authors

Follow this and additional works at: https://arrow.tudublin.ie/cenresart

Part of the Materials Science and Engineering Commons, and the Mechanical Engineering Commons

\section{Recommended Citation}

Sankalp Agarwal, Brendan Duffy, James Curtin, and Swarna Jaiswal, Effect of High- and Low-MolecularWeight Hyaluronic-Acid-Functionalized-AZ31 Mg and Ti Alloys on Proliferation and Differentiation of Osteoblast Cells, ACS Biomaterials Science \& Engineering 20184 (11), 3874-3884 DOI: 10.1021/ acsbiomaterials.8b00968

This Article is brought to you for free and open access by the Crest: Centre for Research in Engineering Surface Technology at ARROW@TU Dublin. It has been accepted for inclusion in Articles by an authorized administrator of ARROW@TU Dublin. For more information, please contact arrow.admin@tudublin.ie, aisling.coyne@tudublin.ie,gerard.connolly@tudublin.ie. Funder: Technological University Dublin 


\section{Authors}

Sankalp Agarwal, Brendan Duffy, James Curtin, and Swarna Jaiswal 


\title{
Effect of High- and Low-Molecular-Weight Hyaluronic-Acid- Functionalized-AZ31 Mg and Ti Alloys on Proliferation and Differentiation of Osteoblast Cells
}

\author{
Sankalp Agarwal, ${ }^{\dagger, \dagger}$ Brendan Duffy, ${ }^{\dagger}$ James Curtin, ${ }^{\dagger}$ and Swarna Jaiswal ${ }^{*}, \dagger$ \\ ${ }^{\dagger}$ Centre for Research in Engineering and Surface Technology, Dublin Institute of Technology, Kevin Street, Dublin 8, Ireland \\ ${ }^{\ddagger}$ School of Food Science and Environmental Health, Dublin Institute of Technology, Cathal Brugha Street, Dublin 1, Ireland
}

Supporting Information

\begin{abstract}
The quality of patient care has increased dramatically in recent years because of the development of lightweight orthopedic metal implants. The success of these orthopedic implants may be compromised by impaired cytocompatibility and osteointegration. Biomimetic surface engineering of metal implants using biomacromolecules including hyaluronic acid (HA) has been used an effective approach to provide conditions favorable for the growth of bone forming cells. To date, there have been limited studies on osteoblasts functions in response to metal substrates modified with the hyaluronic acid of different molecular weight for orthopedic applications. In this study, we evaluated the osteoblasts functions such as adhesion, proliferation, and differentiation in response to high- and lowmolecular-weight HA (denoted as h-HA and l-HA, respectively)

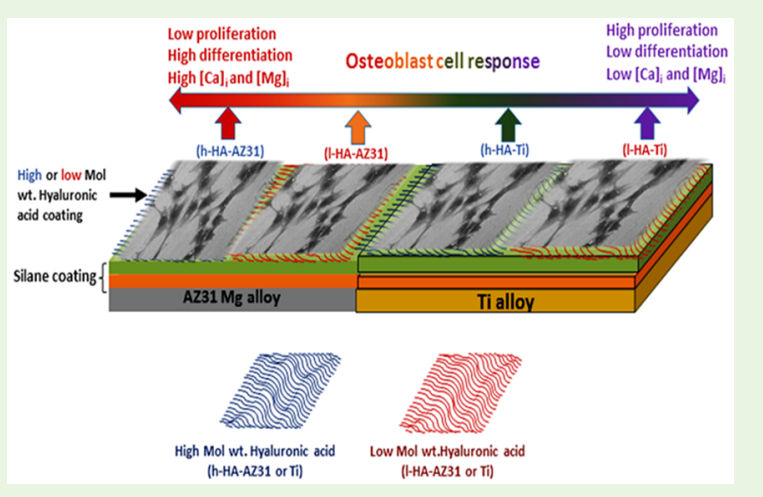
functionalized on $\mathrm{Ti}$ (h-HA-Ti and l-HA-Ti substrates, respectively) and corrosion-resistant silane coated-AZ31 Mg alloys (hHA-AZ31 and 1-HA-AZ31). The DNA quantification study showed that adhesion and proliferation of osteoblasts were significantly decreased by h-HA immobilized on Ti or AZ31 substrates when compared to low-molecular-weight counterpart over a period of 14 days. On the contrary, h-HA significantly increased the osteogenic differentiation of osteoblast over l-HA, as confirmed by the enhanced expression of ALP, total collagen, and mineralization of extracellular matrix. In particular, the h-HAAZ31 substrates greatly enhanced the osteoblast differentiation among tested samples (1-HA-AZ31, l-HA-Ti, h-HA-Ti, and Ti alone), which is ascribed to the osteoinductive activity of h-HA, relatively up-regulated intracellular $\mathrm{Ca}^{2+}\left(\left[\mathrm{Ca}^{2+}\right]_{\mathrm{i}}\right)$ and $\mathrm{Mg}^{2+}$ $\left(\left[\mathrm{Mg}^{2+}\right]_{\mathrm{i}}\right)$ concentrations as well as the alkalization of the cell culture medium. This study suggesting that HA of appropriate molecular weight can be successfully used to modify the surface of metal implants for orthopedic applications
\end{abstract}

KEYWORDS: hyaluronic acid, molecular weight, proliferation, differentiation, magnesium alloy, titanium alloy

\section{INTRODUCTION}

Conventional or biodegradable metallic biomedical implants have been used for clinical applications requiring load-bearing capacities. ${ }^{1}$ Traditionally, conventional metallic orthopedic implants are made up of biostable materials such as stainless steel, cobalt-chromium, and Ti-based alloys. ${ }^{1}$ Among these metals, Ti-based alloys have been widely used to manufacture devices in the forms of screw, pins, or plates, often used to secure fractures in human bone. ${ }^{2}$ However, these implants are prone to postoperative failure because of the mismatch of their mechanical properties to that of natural bone, in addition to complications arising because of inflammation, stress shielding, and physical irritation. ${ }^{1}$ To overcome these drawbacks, researchers have explored $\mathrm{Mg}$-based biodegradable metals as an alternative material. These alloys possess unique characteristics because of their osteoinductive activity, the resemblance of mechanical properties with bone and biocompatibility. ${ }^{3}$ However, rapid dissolution of Mg-based alloys in physiological conditions causes toxicity to the surrounding tissues. ${ }^{4}$
The corrosion resistance and biocompatibility of $\mathrm{Mg}$-based alloys have been improved through selection of alloying elements, surface treatments (using ion-implants, microarc oxidation) and application of functional coatings. ${ }^{1}$ Generally, the integration of bone with metal orthopedic implants are susceptible to a range of stresses, each increasing the risk of implant loosening over time, which can ultimately lead to device failure and revision surgery. ${ }^{5}$ To improve the biological acceptance of the orthopedic implants and osseointegration, researchers have been trying to enhance the cell interaction with the implant surface by immobilization of extracellular matrix (ECM) components. ${ }^{6,7}$ Of these, hyaluronic acid (HA) is involved in various biological functions such as cell adhesion, proliferation, and differentiation ${ }^{7-9}$ In addition, HA possesses anti-inflammatory, bacteriostatic, fungistatic, pro-angiogeneti,c

Received: August 14, 2018

Accepted: September 16, 2018

Published: September 17, 2018 
and osteoinductive properties. ${ }^{10}$ Generally, the most distributed form of HA in the normal tissue is high molecular weight $\mathrm{HA}$ (hHA) $\left(>1 \times 10^{3} \mathrm{kDa}\right){ }^{11}$ During pathological conditions including tissue repair, h- HA undergoes either hyaluronidase mediated degradation or oxidative hydrolysis to produce low molecular weight $\mathrm{HA}(\mathrm{l}-\mathrm{HA})\left(<1 \times 10^{3} \mathrm{kDa}\right) .{ }^{12} \mathrm{~h}-\mathrm{HA}$ and $\mathrm{l}-\mathrm{HA}$ forms regulate different cellular activities such as cell proliferation and differentiation at different stages of tissue repair or remodelling. ${ }^{10}$ During tissue injury, 1-HA stimulates cell motility and proliferation, exhibiting pro-angiogenic and pro-inflammatory responses. ${ }^{13}$ In contrast to l-HA, h-HA has been shown to improve the differentiation and enhance or maintain the cell-cell communication. ${ }^{14}$ However, the exact role of the h- HA during tissue healing has not been assessed conclusively. Based on previous studies, h-HA is thought to play an important role during later stages of bone remodelling by enhancing the differentiation of osteoprogenitor cells or osteoblast lineage cells, thereby aiding to achieve an original biological state of the tissue. ${ }^{9,10,15}$ Because there is a clear distinction in the biological activity of HA-based on molecular weight, where it can be functionalized onto the metal implants by different applications. However, many reported studies functionalized $\mathrm{HA}$ on $\mathrm{Ti}$ alloys without considering the biological properties of HA. ${ }^{5,6}$ This shortcoming may have prevented the exploitation of untapped bone forming potential of hyaluronic acid for given applications. Magnesium-based alloys have also been subjected to various surface modifications to enhance their corrosion resistance and biocompatibility. ${ }^{1}$ In addition, low levels of $\mathrm{Mg}^{2+}$ released in the surrounding medium due to controlled degradation of Mg-based alloys has been shown to improve the osteoblastic activity. ${ }^{16-18}$ However, rapid degradation of $\mathrm{Mg}$ alloys leads to alkalization of the surrounding medium $(\mathrm{pH}>9)$ causing toxicity of the bone-related cells. ${ }^{3,19}$ Previous studies employed various strategies to improve the cytocompatibility and osseointegration of Mg-based alloys using surface functionalization of biomacromolecules such as collagen, albumin, heparin, chitosan, or their composites ${ }^{1,20}$ Our previous study showed that hyaluronic acid functionalized on treated AZ31 substrates enhanced the osteoblastic activity as compared to the bare alloy. ${ }^{21}$ This improved cytocompatibility is attributed to the osteoinductive property of $\mathrm{HA}$ and controlled degradation of the AZ31-Mg alloy. However, the assessment of osteoblasts functions and the mechanisms involved in response to different molecular weights of $\mathrm{HA}$ and extracellular $\mathrm{Mg}^{2+}$ have not been explored to date.

In this study, low- and high-molecular-weight HA (denoted as 1-/h-HA) was grafted onto silane-coated AZ31 (1-/h-HA-AZ31) and $\mathrm{Ti}$ (1-/h-HA-Ti). The fabrication of coating on AZ31 Mg alloy involves an initial MTES-TEOS sol-gel treatment, followed by APTES to deliver an amine terminated surface (as described previously ${ }^{3}$ ) which can be covalently coated with l-HA and h-HA via EDC-NHS coupling reactions. Our previous studies showed that the multifunctionality of this assembly of silane coating not only improves the corrosion protection of AZ31 Mg alloy but also facilitates the functionalization of bioactive biomacromolecules. The effect of 1-/h-HA functionalized $\mathrm{Ti}$ and $\mathrm{AZ} 31 \mathrm{Mg}$ alloys on osteoblast cell proliferation, differentiation and functions were evaluated. In addition, the cellular mechanisms by which h-HA and 1-HA along with $\mathrm{Mg}^{2+}$ conditioned the medium affecting the differentiation of osteoblasts were also studied.

\section{EXPERIMENTAL SECTION}

2.1. Material. AZ31 alloy sheets were obtained from Shaanxi Taipu Rare Metal Materials Ltd., China. Methyltriethoxysilane, tetraethoxysilane, 3-aminopropyl-triethoxysilane, high-molecular-weight hyaluronic acid from rooster comb (1-4 MDa), low-molecular-weight hyaluronic acid from Streptococcus equi. spp. $(30-50 \mathrm{kDa})$ phosphate buffer saline (PBS), Dulbecco's modified Eagle's medium/nutrient F12 ham (DMEM/F-12), fetal bovine serum (FBS), penicillinstreptomycin antibiotics, phosphatase substrate, and bisbenzimide $\mathrm{H}$ 33342 trihydrochloride, NHS ( $\mathrm{N}$-Hydroxysuccinimide), EDC (1ethyl-3-(3-(dimethylamino)propyl)carbodiimide), and MES (2-(NMorpholino)ethanesulfonic acid) buffer were purchased from SigmaAldrich.

2.2. Surface Modifications of $\mathrm{AZ31} \mathrm{Mg}$ and Ti Alloys. 2.2.1. Treatment of $A Z 31$ and Ti with $\mathrm{NaOH}$. Two millimeter thick sheets of AZ31 Mg and Ti alloy (Ti-6Al-4 V) were cut into $10 \times 10 \mathrm{~mm}$ coupons and polished progressively by finer $\mathrm{SiC}$ paper from 400 to 1200 grit. The samples were cleaned ultrasonically in ethanol and immersed in $5 \mathrm{~N} \mathrm{NaOH}$ for $2 \mathrm{~h}$ at $60^{\circ} \mathrm{C}$ and then rinsed with deionized water. ${ }^{19}$ The $\mathrm{NaOH}$ treated $\mathrm{AZ} 31-\mathrm{Mg}$ and $\mathrm{Ti}$ alloys are referred to as AZ31-OH and $\mathrm{Ti}-\mathrm{OH}$ substrates, respectively.

2.2.2. Preparation of the Hyaluronic Acid Functionalized Silane Coating on AZ31 Mg and Ti Alloy. The MTES-TEOS hybrid sol was prepared in the ethanol solution containing $0.04 \mathrm{~N}$ nitric acid as a catalyst. The MTES and TEOS were mixed in a molar ratio of 2:1 with $R=2.36$, where $R=\left[\mathrm{H}_{2} \mathrm{O}\right] /$ [MTES+TEOS]. The APTES sol was prepared using $400 \mathrm{mM}$ APTES in ethanol solution with $R=4.5(R=$ $\left[\mathrm{H}_{2} \mathrm{O}\right] /[$ APTES $\left.]\right)$. The AZ31-OH and Ti-OH substrates were dipcoated sequentially in MTES-TEOS (AZ31-MT or Ti-MT) and APTES (A) sol-gels and cured at $120^{\circ} \mathrm{C}$ for $1 \mathrm{~h}$ at each step to achieve the amine-terminated AZ31-MT-A and Ti-MT-A surfaces. ${ }^{3}$ Furthermore, $1 \mathrm{mg} / \mathrm{mL}$ high- and low-molecular-weight HA solutions were used to functionalize AZ31-MT-A and Ti-MT-A substrates by a carbodiimide-mediated coupling reaction as detailed in the previous study. ${ }^{7,21,22}$ The resultant high- and low-molecular HA-functionalized AZ31-MT-A or Ti-MT-A substrates are denoted as h-HA-AZ31, 1-HAAZ31, h-HA-Ti , and l-HA-Ti substrates, respectively.

The concentration of 1-/h-HA immobilized on the silane coated AZ31 or Ti substrate was quantified by the Morgan-Elson fluorometric enzyme assay. ${ }^{23}$ The 1-/h-HA-AZ31 and 1-/h-HA-Ti substrates were exposed to the hyaluronidase enzyme for an appropriate time at 37.5 ${ }^{\circ} \mathrm{C}$. Then, the enzyme solution was incubated in a boiling water bath for $5 \mathrm{~min}$ to inactivate the enzymatic activity. The enzyme solutions were cooled to room temperature and $25 \mu \mathrm{L}$ of tetraborate reagent was added and incubated in a boiling water bath for $3 \mathrm{~min}$ to start the Morgan-Elson fluorometric reaction. The solutions were cooled to room temperature and $0.75 \mathrm{~mL}$ of $10 \% \mathrm{w} / \mathrm{v}$ DMAB (p-dimethylaminobenzaldehyde) reagent was added and incubated for $20 \mathrm{~min}$ at 37.5 ${ }^{\circ} \mathrm{C}$. The release of $\mathrm{N}$-acetyl glucosamine was determined by fluorescence spectroscopy (Ex/Em: 545/604 nm). The concentration of HA functionalized was quantified using a standard curve of HA.

2.3. Characterization of Modified AZ31 and Ti Substrates. The wettability of AZ31 (1-/h-HA-AZ31) and Ti (1-/h-HA-AZ31) modified and uncoated substrates were determined by static water contact angle measurements (FTÅ-200 system, UK). The surface morphology of the substrates was studied by an atomic force microscope (AFM, Asylum MFP-3D-BIO, USA).

2.4. Cytocompatibility. 2.4.1. Imaging of Osteoblast Morphology by SEM. The morphology of osteoblast cells seeded at a density of $10^{4}$ cells.cm ${ }^{-2}$ on the experimental substrates was observed after $24 \mathrm{~h}$ of cell culture. ${ }^{24}$ Cells were cultured under $37{ }^{\circ} \mathrm{C}, 5 \% \mathrm{CO}_{2}$ and $95 \%$ relative humidity in DMEM/F-12 containing 10\% FBS and $1 \%$ antibiotic-antimycotic. Cells were seeded $\left(1 \times 10^{4}\right.$ cells.cm $\left.{ }^{-2}\right)$ on hHA-AZ31, l-HA-AZ31, h-HA-Ti, l-HA-Ti, and uncoated AZ31 and Ti substrates, and maintained in complete DMEM/F12 $\left(1 \mathrm{~cm}^{2}=1.25\right.$ $\mathrm{mL}$ ) in accordance with ISO 10993-12 ${ }^{3}$. After incubation, the substrates were washed with PBS, fixed with formalin and dehydrated in alcohol gradients. The substrates were sputter-coated with $\mathrm{Au}-\mathrm{Pd}$ and observed by SEM. ${ }^{25}$ 
2.4.2. DNA Quantification. The total cellular DNA content of MC3T3E1 osteoblast cells was considered as a measure of cell adhesion and proliferation. ${ }^{19}$ Osteoblasts were cultured on the coated and uncoated AZ31 substrates at a density of $2.5 \times 10^{4}$ cells cm $\mathrm{cm}^{-2}$ for 3,7 , and 14 days in a differentiation medium. ${ }^{3}$ The differentiation medium was prepared by adding $50 \mu \mathrm{M}$ ascorbic acid, $100 \mathrm{nM}$ dexamethasone, and $10 \mathrm{mM} \beta$-glycerophosphate in F12/DMEM. ${ }^{19}$ For the cell adhesion study, cells were cultured in normal cell culture medium (nonosteoinductive medium) for $24 \mathrm{~h}$. After 1, 3, 7, and 14 day(s) of culture, substrates were washed with PBS and the cells were lysed using cell lysis buffer. ${ }^{3}$ The fluorescent dye, Hoechst 33258 (Sigma-Aldrich) was used to quantify the cellular DNA according to the manufacturer's instructions (DNA quantification kit, Sigma-Aldrich).

2.4.3. Alkaline Phosphatase (ALP) Assay. The differentiation of osteoblast cells was studied by measuring intracellular ALP activity using a para-nitrophenyl phosphate substrate (p-NPP, Sigma). ${ }^{26}$ After 3,7 , and 14 days of osteoblasts cultured in the differentiation medium, the cell lysate was incubated with p-NPP for $1 \mathrm{~h}$ at $37{ }^{\circ} \mathrm{C}$. The enzymatic reaction was terminated by adding $1 \mathrm{~N} \mathrm{NaOH}$ and the ALP activity was measured by the UV absorbance of para-nitrophenol ( $\mathrm{p}$ $\mathrm{NP}$ ) at $410 \mathrm{~nm}$. A standard curve of different $\mathrm{p}-\mathrm{NP}$ concentrations was prepared by diluting in $0.02 \mathrm{~N} \mathrm{NaOH}$. The p-NP was normalized against total protein concentration. The total protein content was determined by using the bicinchoninic acid protein assay kit (SigmaAldrich).

2.4.4. Quantification of Magnesium and Calcium lons. After 3, 7, and 14 days of cell culture under differentiation conditions, osteoblasts were scrapped and lysed using cell lysis buffer. ${ }^{25} \mathrm{The}_{\mathrm{Mg}^{2+}}$ and $\mathrm{Ca}^{2+}$ in the cell lysate were determined using respective magnesium and calcium assays kit (Sigma-Aldrich). The intracellular $\mathrm{Mg}^{2+}$ and $\mathrm{Ca}^{2+}$ concentrations were measured by absorbance at 450 and $575 \mathrm{~nm}$, respectively. Standards curves were prepared as per kit instructions. The $\mathrm{Mg}^{2+}$ concentration in the culture medium was also determined using a magnesium assay kit (Sigma-Aldrich).

2.4.5. Total Collagen Content. The total collagen content of all the samples was determined using a hydroxyproline assay kit (SigmaAldrich). Osteoblasts cultured on different substrates for 3,7 and 14 days under differentiation conditions were scraped and subjected to acid hydrolysis using $12 \mathrm{~N} \mathrm{HCl}$ for $12 \mathrm{~h}$ incubated at $100{ }^{\circ} \mathrm{C}^{27}$ Thereafter, the instructions given in the kit were followed and the absorbance was measured at $405 \mathrm{~nm}$. The total hydroxyproline content was calculated using standards provided in the kit.

2.4.6. Assessment of Osteoblasts Mineralization Using SEM-EDX. After 14 days of culture, osteoblast-adhered samples were washed thrice with PBS and fixed with formalin. The cell-fixed samples were dehydrated in alcohol gradients. After sputter-coating with $\mathrm{Au}-\mathrm{Pd}$, the elemental content of the adhered cells on different substrates was determined using SEM-EDX. ${ }^{25}$

2.5. Statistical Analysis. All of the experiments were conducted in triplicate. All data are expressed as mean \pm SD. The differences between the groups were analyzed using one-way analysis of variance (ANOVA) followed by post hoc Tukey test.

\section{RESULTS}

3.1. Characterization of Modified AZ31 and Ti Substrates. The functionalization of 1-HA and h-HA on AZ31 and Ti substrates was confirmed using AFM, static water contact angle and HA quantification as shown in Table 1 . The surface roughness $\left(R_{\mathrm{a}}\right)$ of uncoated AZ31 and Ti substrates were found to be $47.43 \pm 4.11 \mathrm{~nm}$ and $14.5 \pm 2.11 \mathrm{~nm}$, respectively. The 1-HA functionalized on AZ31 and Ti substrates showed slightly reduced surface roughness as compared to h-HA functionalized AZ31/Ti substrates. The AFM images of these substrates are given inI Figure S1. Overall, the roughness of substrates reduced for HA-functionalized AZ31/Ti substrates when compared to respective uncoated substrates.

The static water contact angle was determined to confirm the wettability of the uncoated and coated substrates as shown in
Table 1. Summary of Characterization Parameters for Different Substrates

\begin{tabular}{lccr}
\multicolumn{1}{c}{ substrates } & roughness $(\mathrm{nm})$ & contact angle $($ degrees $)$ & $\mathrm{HA}\left(\mu \mathrm{g} / \mathrm{cm}^{2}\right)$ \\
AZ31 & $47.43 \pm 4.11$ & $59.67 \pm 6.99$ & \\
h-HA-AZ31 & $11.29 \pm 0.21$ & $44.22 \pm 3.58$ & $47.62 \pm 1.05$ \\
l-HA-AZ31 & $7.67 \pm 0.17$ & $36.06 \pm 2.03$ & $41.58 \pm 2.05$ \\
h-HA-Ti & $8.66 \pm 0.58$ & $40.54 \pm 3.03$ & $48.51 \pm 0.02$ \\
l-HA-Ti & $7.08 \pm 0.71$ & $26.62 \pm 4.46$ & $40.6 \pm 1.49$ \\
Ti & $14.5 \pm 2.11$ & $45.31 \pm 5.92$ & \\
\hline
\end{tabular}

Table 1. The l-HA coated AZ31 $\left(36.06^{\circ} \pm 2.03\right)$ and $\mathrm{Ti}\left(26.62^{\circ}\right.$ $\pm 4.46)$ substrates showed relatively higher hydrophilic surface as compared to h-HA functionalized AZ31 $\left(44.22^{\circ} \pm 3.58\right)$ and $\mathrm{Ti}\left(40.54^{\circ} \pm 3.03\right)$ substrates. The HA-coated substrates showed a considerable increase in the wettability of surface when compared to the uncoated AZ31 $\left(59.67^{\circ} \pm 6.99\right)$ and $\mathrm{Ti}\left(45.31^{\circ}\right.$ $\pm 5.92)$ substrates. AFM images are given in the Supporting Information.

Furthermore, the concentration of HA immobilized on the surface was quantified as given in Table 1 . The concentrations of h-HA immobilized on AZ31 and Ti substrate were found to be similar, $\sim 48 \mu \mathrm{g} / \mathrm{cm}^{2}$, whereas 1-HA showed the lower concentration of $\sim 41 \mu \mathrm{g} / \mathrm{cm}^{2}$.

3.2. Osteoblast Cell Adhesion. Representative SEM images of osteoblasts adhered to AZ31 Mg and Ti alloys treated with or without 1-HA and h-HA are shown in Figure 1(I). After $24 \mathrm{~h}$ of incubation, osteoblasts are sparse and showed circular morphology on the uncoated AZ31 Mg alloy (Figure $2 \mathrm{I}(\mathrm{a})$ ), demonstrating poor adhesion to the substrate. The h-AZ31-HA (Figure 2I(b)) and 1-AZ31-HA (Figure 2I(c)) surfaces showed flattened, cuboidal-shaped, and extended morphology of adhered osteoblast cells with greater cell-to-cell interaction. On the other hand, the h-HA-Ti (Figure 2I(d)) and l-HA-Ti (Figure 2I(e)) surfaces showed triangular or irregular shaped morphology of the attached osteoblast cells. The Ti substrate control showed a greater number of adhered osteoblasts with spindle-shaped morphologies. Figure 1(II) shows the quantification of total DNA content on these substrates, which is considered as a measure of a number of osteoblasts adhered to the surface. The DNA content of osteoblasts on the AZ31 Mg alloy was found to be significantly lower when compared to all substrates. Poor adherence of osteoblasts to the HA-coated AZ31 surfaces was observed when compared to HA-coated Ti or $\mathrm{Ti}$ alone substrates. Interestingly, 1-HA-coated $\mathrm{Ti}$ substrate showed significantly improved cell adhesion over h-HA-Ti, hHA-AZ31, and l-HA-AZ31 substrates.

3.3. Osteoblast Cell Proliferation. Figure 2 shows the quantification of the total DNA content of osteoblasts cultured on different substrates over a period of 14 days. The quantification of total DNA content was considered as a measure of cell proliferation. Because bare AZ31 substrate showed high cytotoxicity with very few live cells as observed in Figure 1, it was considered futile to use this as a control for further studies.

From Figure 2, it can be noted that osteoblast proliferation on 1-HA-AZ31 and 1-HA-Ti was found to be significantly higher as compared to that on h-HA-AZ31 and h-HA-AZ31, respectively, over 14 days of cell culture. Among all substrates, bare Ti alloy showed significantly enhanced osteoblast cell proliferation. These results are in agreement with SEM images and cell adhesion studies, indicating that l- HA promotes osteoblast cell proliferation over h-HA. 

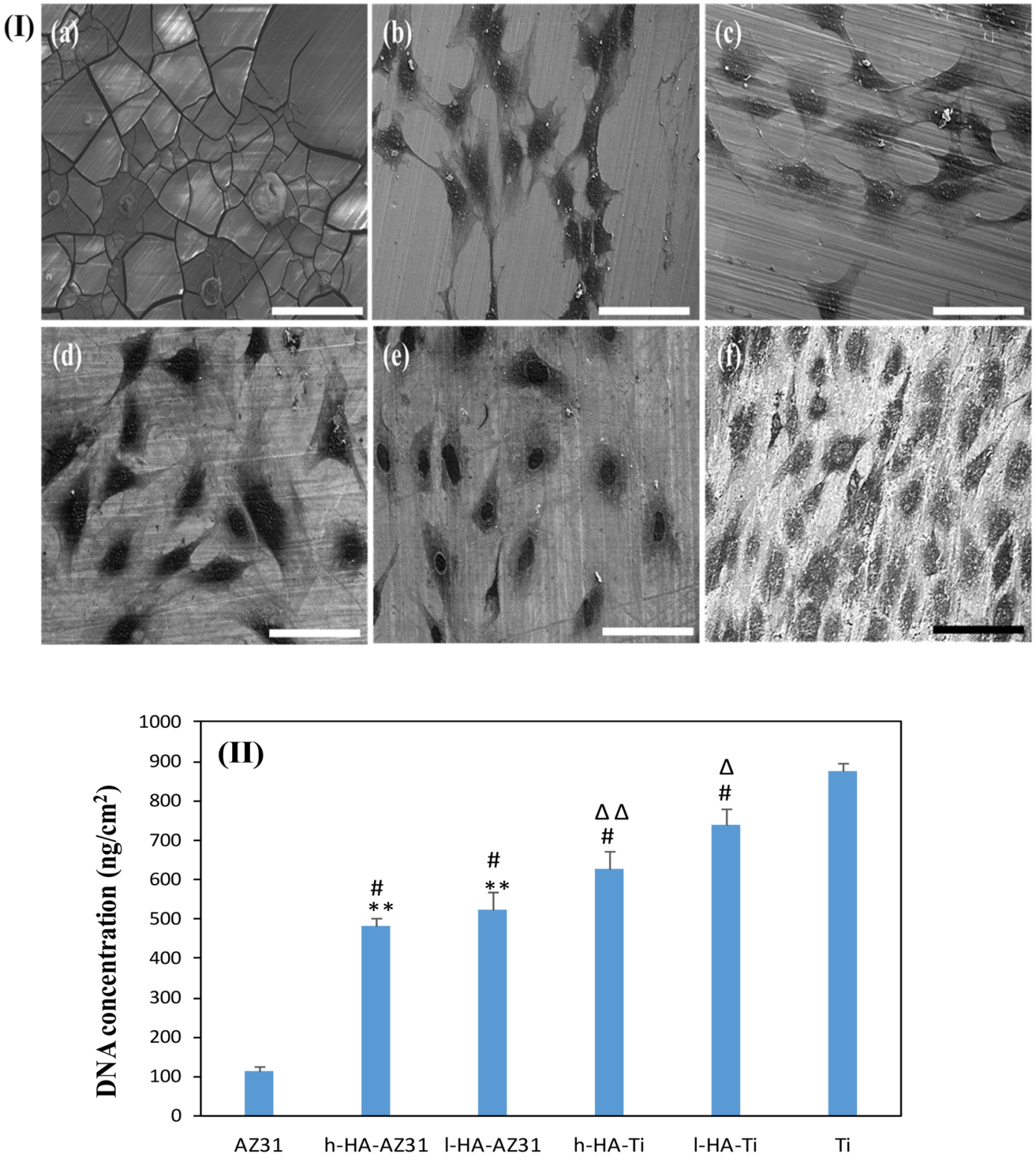

Substrates

Figure 1. (I) SEM images of osteoblasts adhered on (a) AZ31, (b) h-HA-AZ31, (c) l-HA-AZ31, (d) h-HA-Ti, (e) l-HA-Ti, and (f) Ti substrates for 24 h. (II) Total DNA content of osteoblast cells cultured on different substrates for $24 \mathrm{~h}$. The scale of SEM images is $100 \mu \mathrm{m}$. Statistical analysis: Values are expressed as mean \pm SD. One-way ANOVA with posthoc Tukey test with significance level of $* * P<0.01$ versus AZ31 control; \#P<0.05 indicates the comparison of 1-/h-HA-AZ31 with the 1/h-HA-Ti group; $\Delta P<0.05$ and $\Delta \Delta P<0.01$ indicate the comparison of Ti with the l-/h-HA-Ti group.

3.4. Osteogenic Differentiation of Osteoblasts. Differentiation markers of osteoblasts cultured on HA-coated substrates under osteogenic condition were screened as shown in Figure 3.

The ALP activity of osteoblasts cultured on l-/h-HA-AZ31/Ti coated substrates determined for 14 days as shown in Figure 3a. Osteoblasts cultured on 1-HA-AZ31 and 1-HA-Ti showed significantly low ALP activity as compared to h-HA-AZ31 and h-HA-Ti respectively, over a period of 14 days. Overall, osteoblasts cultured on HA-functionalized AZ31 Mg surface exhibited reduce intracellular ALP levels as compared to the HA$\mathrm{Ti}$ surface. The bare $\mathrm{Ti}$ alloy induced the highest level of intracellular ALP expression. Furthermore, ALP activity was normalized to total DNA content of respective samples (Figure 3a). This result shows that h-HA coated AZ31/Ti substrates significantly enhanced the ALP activity of osteoblasts when compared to the 1-HA-coated AZ31/Ti substrates, whereas the Ti substrate showed lowest ALP activity during 14 days of the culture period. The order of ALP expression showed by the coated substrates is h-HA-AZ31 > h-HA-Ti> l-HA-AZ31 > 1$\mathrm{HA}-\mathrm{Ti}>\mathrm{Ti}$. These results indicated that magnesium alloy substrate and h-HA synergistically induce the intracellular ALP activity of osteoblast cells.

Furthermore, the expression of total collagen by osteoblast in response to $1-/ \mathrm{h}-\mathrm{HA}$ coated on $\mathrm{AZ} 31 / \mathrm{Ti}$ substrates was evaluated using the hydroxyproline assay as shown in Figure $3 \mathrm{~b}$. The total collagen content normalized to DNA increased with the culture period of 14 days. In particular, the h-HA-AZ31 surface $(P<0.01)$ significantly stimulated the collagen synthesis when compared to l-HA-AZ31, h-HA-Ti, l-HA-Ti, and Ti 


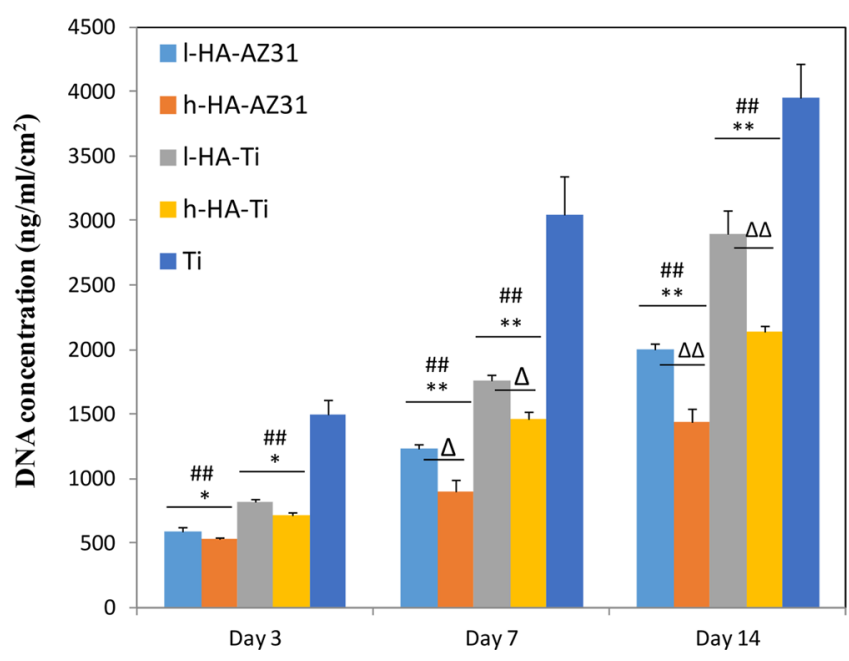

Figure 2. Total DNA content was determined following osteoblasts culture on AZ31, l-HA-AZ31, h-HA-AZ31, l-HA-Ti, h-HA-Ti, and Ti substrates for 3, 7, and 14 days. Statistical analysis: Values are expressed as mean $\pm \mathrm{SD}$. One-way ANOVA with posthoc Tukey test with significance level of $* P<0.05, * * P<0.01$ indicating the comparison between 1-/h-HA-AZ31 and 1-/h-HA-Ti substrates ; \#\#P $<0.01$ indicates comparison between different samples (1-/h-HA-AZ31 and l-/ h-HA-Ti substrates) versus $\mathrm{Ti} ; \Delta P<0.05$ and $\Delta \Delta P<0.01$ indicate the pairwise comparison of samples.

equivalents. Furthermore, h-HA-Ti also showed a significant increase in total collagen content as compared to 1-HA-Ti and bare Ti substrates. The expression level of collagen was found to be in the order of h-HA-AZ31 > l-HA-AZ31 > h-HA-Ti > l-HA$\mathrm{Ti}>\mathrm{Ti}$. A similar trend was also observed for the overall expression of collagen (not normalized to DNA) on the substrate (Figure S2). These results are in agreement with the intracellular ALP enzyme activity, thereby indicating that h-HA and AZ31 Mg alloy induced an enhanced differentiation as compared to the 1-/h-HA-coated Ti alloy.

Figure 4 shows the representative SEM images of mineralization of osteoblasts cultured under the osteogenic condition for 14 days.

Compared with 1/h-HA-Ti (Figure 4c, d), deposits of calcium (Ca) and phosphate (P) mineral particles/nodules can be observed around the osteoblasts cultured on 1-/h-HA-AZ31 surfaces. On the other hand, uniformly distributed $\mathrm{Ca}-\mathrm{P}$ mineral particles observed on and around the osteoblasts adhered to l-/h-HA-Ti and Ti only substrates. Furthermore, the elemental analysis of osteoblasts cultured on different substrates for 14 days is presented in Table 2.

From Table 2, Ca and P contents (at. wt \%) detected on 1-HATi $(\sim 29$ and $\sim 17 \%)$ and h-HA-Ti $(\sim 31 \%$ and $\sim 19 \%)$ were found to be higher than l-HA-AZ31 $(\sim 8.5$ and $\sim 6 \%)$ and h-HAAZ31 ( $\sim 16$ and $\sim 12 \%)$ respectively. Notably, AZ31-HA, Ti-HA and $\mathrm{Ti}$ without cells also showed $\mathrm{Ca}$ and $\mathrm{P}$ deposition. Since minor differences in element deposition on 1-HA-AZ31/Ti and h-HA-AZ31/Ti controls were observed, an average of their elemental analysis is represented as AZ31-HA (w/o cells) and Ti-HA (w/o cells) samples. Interestingly, l-/h-HA-Ti surface showed considerable higher $\mathrm{Ca}$ and $\mathrm{P}$ depositions when compared to the 1-/h-HA-AZ31 and Ti substrates. This indicated a very high content of nonspecific $\mathrm{Ca}$ and $\mathrm{P}$ deposits on $\mathrm{Ti}$ (w/o cells) and $\mathrm{Ti}-\mathrm{HA}$ (w/o cells) substrates which makes up $\sim 83 \%$ of $\mathrm{Ca}$ and $\sim 76-80 \%$ of $\mathrm{P}$ deposition of the corresponding substrates (l-HA-Ti, h-HA-Ti, and $\mathrm{Ti}$ ) with osteoblasts. On the other hand, a considerably low nonspecific mineral deposition was observed for AZ31-HA (w/o cells) samples, with deposits of $\sim 2-4 \%$ of $\mathrm{Ca}$ and $\sim 7-15 \%$ of $\mathrm{P}$ on the 1-HA-AZ31 and h-HA-AZ31 substrates, respectively. Therefore, osteoblasts cultured on 1/h-HA-AZ31 substrates showed a greater degree of mineralization, when compared to $1 / \mathrm{h}-\mathrm{HA}-\mathrm{Ti}$ equivalent as shown in Table 2.

Furthermore, Mg-based alloys degrade rapidly under physiological conditions, thereby creating an alkaline environment that interferes with the cell physiology. ${ }^{25}$ The degradation of HA-coated AZ31 Mg alloy (with and without osteoblasts) and change in $\mathrm{pH}$ of the medium during a culture period of 14 days are exhibited in Figure 5.

The concentration of $\mathrm{Mg}^{2+}$ released from the AZ31-HA substrate ( $\mathrm{w} / \mathrm{o}$ cells) was found to significantly higher than $1-$ HA-AZ31, h-HA-AZ31 and cell culture medium (CCM) samples over a period of 14 days, as shown in Figure 5a. However, the release of the $\mathrm{Mg}^{2+}$ from AZ31-HA (w/o cells) substrate is significantly lower than the uncoated AZ31 Mg alloy as shown in Figure S3. This indicated that the improved corrosion resistance of HA functionalized silane coated AZ31 substrate when compared to the uncoated AZ31 substrate. Furthermore, the release of $\mathrm{Mg}^{2+}$ from $1 / \mathrm{h}-\mathrm{HA}-\mathrm{AZ} 31$ and AZ31$\mathrm{HA}$ (w/o cells) decreased steadily with the culture period. The concentration of $\mathrm{Mg}^{2+}$ in CCM containing $1 / \mathrm{h}-\mathrm{HA}-\mathrm{Ti}$ and $\mathrm{Ti}$ substrates is relatively lower than the CCM control, indicating that osteoblasts are using $\mathrm{Mg}^{2+}$ present in the culture medium for the normal physiological process.

Furthermore, change in the $\mathrm{pH}$ of CCM affects the osteoblasts functions. Figure $5 \mathrm{~b}$ shows the bulk change in $\mathrm{pH}$ of the CCM containing different substrates (with and without osteoblast cells) over a period of 14 days. The $\mathrm{pH}$ of the CCM for the Ti-based substrates remains constant around 7.4. On the other hand, the AZ31-based substrates showed alkaline behavior decreasing gradually over 14 days of the culture period. It can be seen that 1/h-HA-AZ31 (w/o cells) showed relatively higher alkaline $\mathrm{pH}(\sim 8.1)$ when compared to 1-HA-AZ31 (with cells, $\mathrm{pH} \sim 7.7$ ) and h-HA-AZ31 substrates (with cells, $\mathrm{pH} \sim 7.8$ ) after 14 days of incubation. These results indicated that osteoblasts monolayer functions in corrosion protection of $\mathrm{AZ3Mg}$ alloy and/or using $\mathrm{Mg}^{2+}$ for cellular growth and development.

Previous studies showed that extracellular $\mathrm{Mg}^{2+}$ (here, $\mathrm{Mg}^{2+}$ concentration in CCM is denoted as $\left[\mathrm{Mg}^{2+}\right]_{\mathrm{e}}$ ) affects the cell behavior by regulating intracellular $\mathrm{Mg}^{2+}$ and $\mathrm{Ca}^{2+}$ concentrations (denoted as $\left[\mathrm{Mg}^{2+}\right]_{\mathrm{i}}$ and $\left[\mathrm{Ca}^{2+}\right]_{\mathrm{i}}$ respectively). To understand the effect of molecular weight of $\mathrm{HA}$ and $\left[\mathrm{Mg}^{2+}\right]_{\mathrm{e}}$ the $\left[\mathrm{Mg}^{2+}\right]_{\mathrm{i}}$ and $\left[\mathrm{Ca}^{2+}\right]_{\mathrm{i}}$ of osteoblasts cultured on 1-/h-HAAZ31, 1-/h-HA-Ti and Ti substrates for 3, 7, and 14 days were examined, as shown in Figure 6.

First, it can be seen that at each time point, 1-/h-HA-AZ31 showed a significantly higher $\left[\mathrm{Mg}^{2+}\right]_{\mathrm{i}}$ as compared to $1-/ \mathrm{h}-\mathrm{HA}-$ $\mathrm{Ti}$ and Ti substrate, whereas no significant change in the $\left[\mathrm{Mg}^{2+}\right]_{\mathrm{i}}$ was observed for Ti-based substrates (1-/h-HA-T and Ti alone) as shown in Figure 6a. Second, 1-/h-HA showed a higher level of $\left[\mathrm{Ca}^{2+}\right]_{\mathrm{i}}$ as compared to l-/h-HA-Ti and Ti substrate (Figure $6 \mathrm{~b}$ ), which is inversely proportional to $\left[\mathrm{Mg}^{2+}\right]_{\mathrm{i}}$ of 1 -/h-HA-AZ31 substrates (Figure 6a). Notably, without much change in $\left[\mathrm{Mg}^{2+}\right]_{\mathrm{i}}$, h-HA-Ti showed a significant increase in $\left[\mathrm{Ca}^{2+}\right]_{\mathrm{i}}$ when compared to the l-HA-Ti, whereas $\mathrm{Ti}$ alone showed the least increase in $\left[\mathrm{Ca}^{2+}\right]_{\mathrm{i}}$. These results indicated that $\left[\mathrm{Mg}^{2+}\right]_{\mathrm{e}}$ acting as a pro-osteogenic agent regardless of the type of HA employed on the surface, whereas h-HA enhanced the pro-osteogenic differentiation as compared to l-HA (Figure 6(b)). 

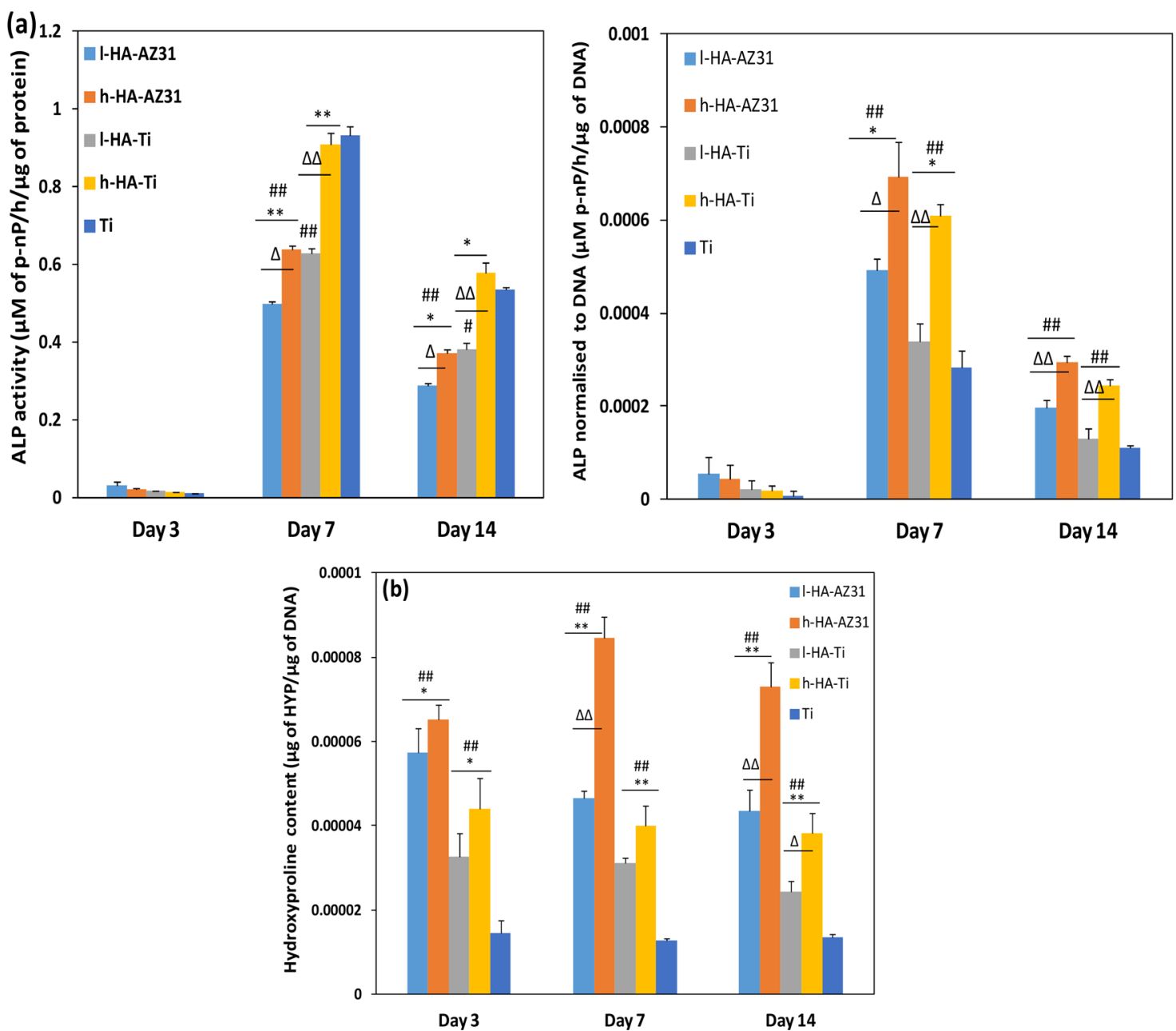

Figure 3. Evaluation of osteogenic differentiation of osteoblasts cultured on l-HA-AZ31, h-HA-AZ31, l-HA-Ti, h-HA-Ti, and Ti substrates for 3, 7, and 14 days using (a) intracellular ALP activity and (b) hydroxyproline content. Statistical analysis: Values are expressed as mean \pm SD. One-way ANOVA with posthoc Tukey test with significance level of $* P<0.05$, $* * P<0.01$ indicating the comparison between $1-/ \mathrm{h}-\mathrm{HA}-\mathrm{AZ} 31$ and $\mathrm{l}-/ \mathrm{h}-\mathrm{HA}-\mathrm{Ti}$ substrates ; $\# P<0.05$, \#\#P $<0.01$ indicate comparison between different samples (1-/h-HA-AZ31 and l-/h-HA-Ti substrates) versus Ti; $\Delta P<0.05$ and $\Delta \Delta P<$ 0.01 indicate the pairwise comparison of samples.
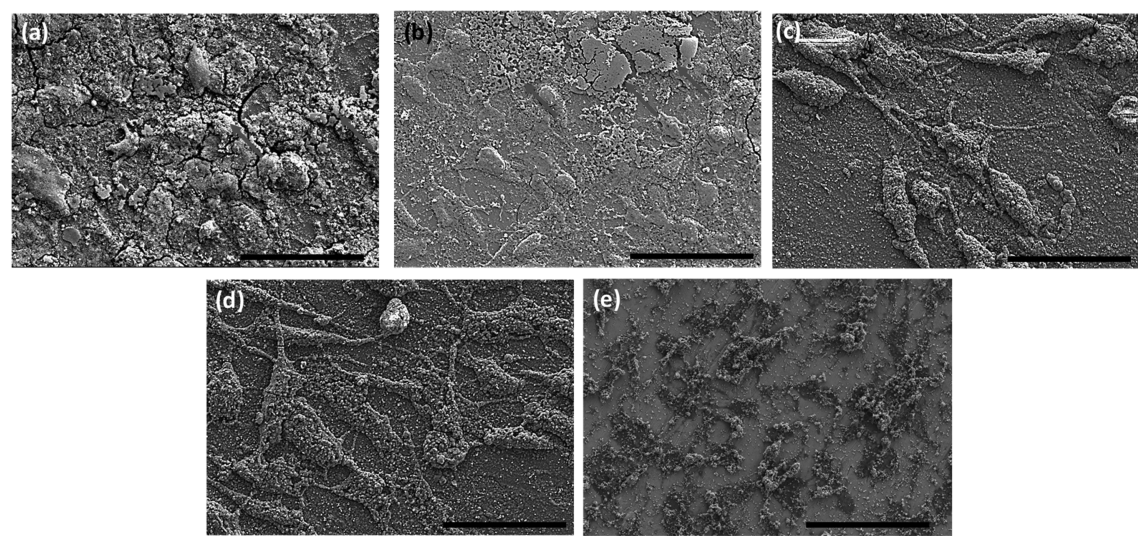

Figure 4. Representative SEM images of osteoblasts cultured on (a) l-HA-AZ31, (b) h-HA-AZ31, (c) l-HA-Ti, (d) h-HA-Ti, and (e) Ti substrates for 14 days in osteogenic CCM. The scale of SEM images is $50 \mu \mathrm{m}$.

\section{DISCUSSION}

The biological acceptance of the orthopedic implants in terms of osteoblasts functions plays a vital role in expediting of bone tissue healing surrounding the implants ( $\mathrm{Ti}-$ and $\mathrm{Mg}$-based implants). In order to improve the cytocompatibility of the implants, various biopolymers including HA has been functionalized onto the metal implant surfaces. ${ }^{20,27,28} \mathrm{HA}$ is present in various body tissues including synovial fluid, the vitreous body of eye, brain and cartilage. ${ }^{29}$ It also plays an important role in regulating various biological processes including osteoblasts cell 
Table 2. Elemental Contents Detected by EDX of Osteoblasts Cultured on Different Substrates for 14 Days ${ }^{a}$

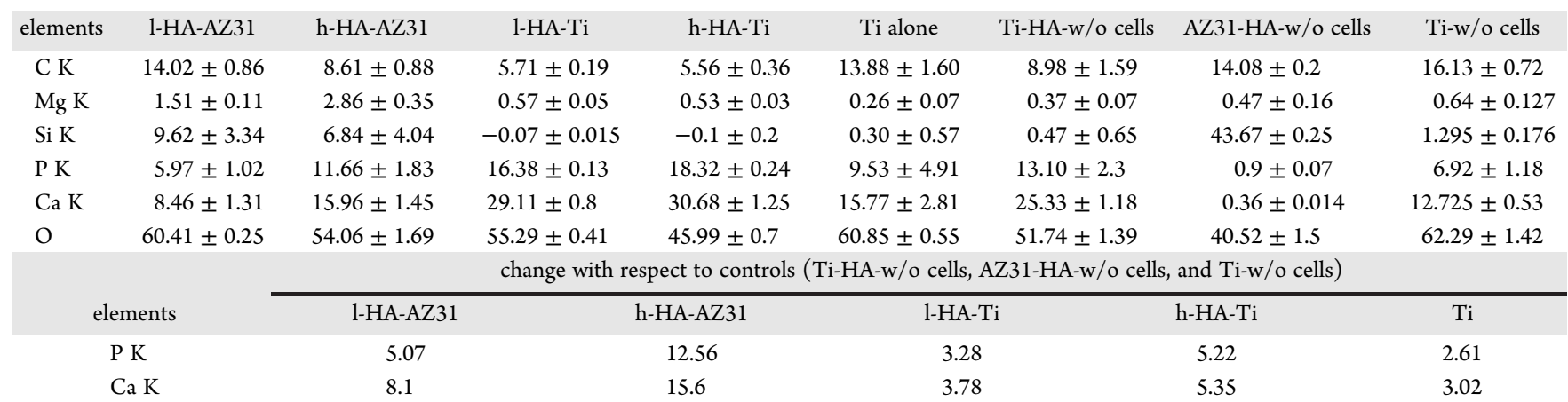

${ }^{a}$ Statistical analysis: Values are expressed as mean \pm SD.
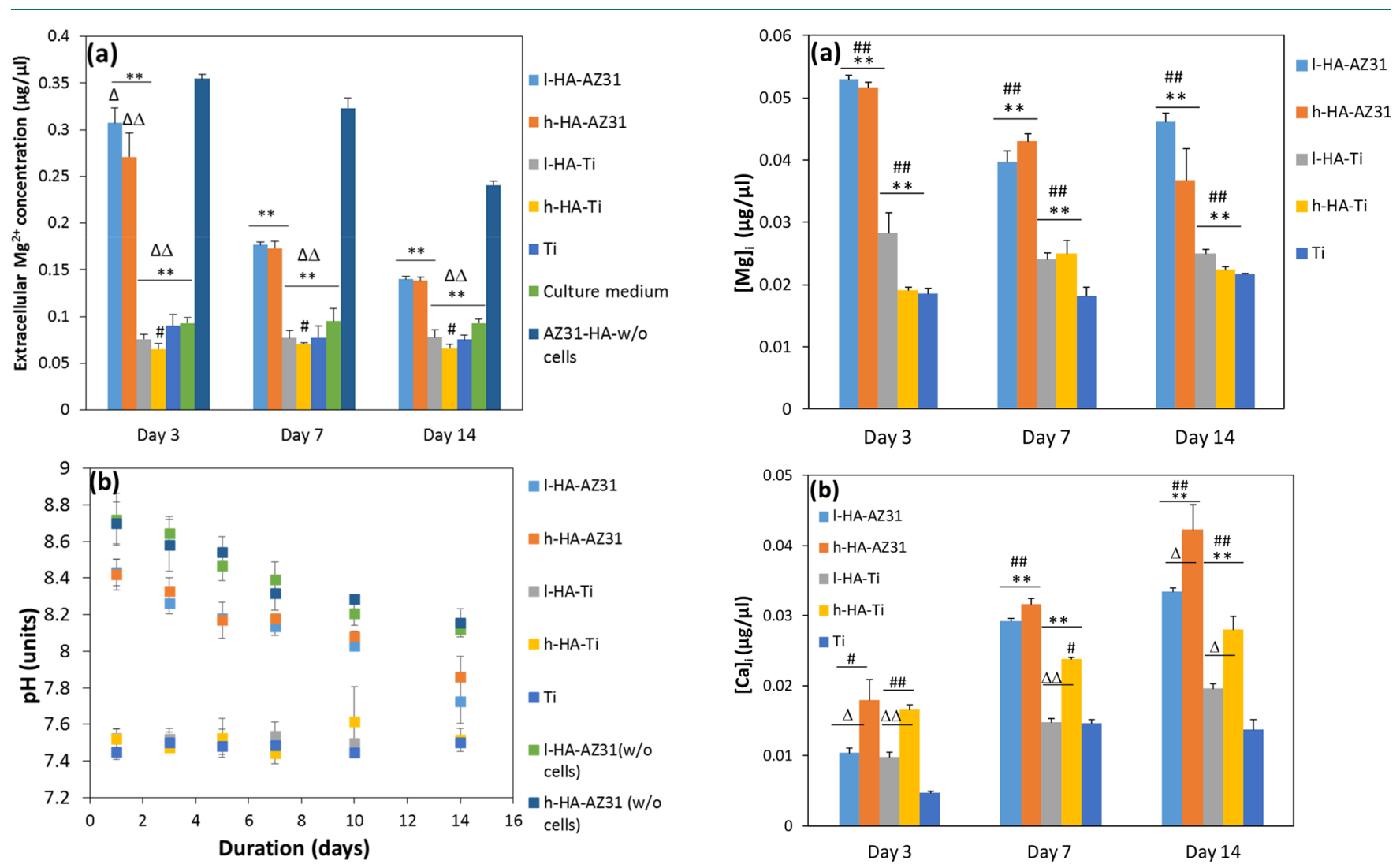

Figure 5. (a) $\mathrm{Mg}^{2+}$ release and (b) $\mathrm{pH}$ change of CCM containing 1HA-AZ31, h-HA-AZ31, 1-HA-Ti, h-HA-Ti, and Ti substrates for 3, 7, and 14 days. Statistical analysis: Values are expressed as mean \pm SD. One-way ANOVA with posthoc Tukey test with significance level of $* P$ $<0.05$, $* * P<0.01$ indicate the comparison of 1-/h-HA-AZ31 substrates versus 1-/h-HA-Ti, Ti, and culture medium ; $\# P<0.05$ comparison of different samples versus culture medium; $\Delta P<0.05$ and $\Delta \Delta P<0.01$ indicate comparison of different samples versus AZ31-HA-w/o cells.

adhesion, proliferation and differentiation. ${ }^{11}$ In previous studies, hyaluronic acid was functionalized with Ti surfaces, to improve osteoblastic activity. ${ }^{6,7,27}$ However, these were fundamental studies and molecular weight of HA as not considered while employing it as an osteoinductive agent. Furthermore, deposit coatings improve the corrosion resistance and cytocompatibility of the biodegradable Mg-based alloys that are widely used for orthopedic application. In this work, we used previously reported corrosion resistant sol-gel coating to develop l-/h-HA functionalized AZ31 and $\mathrm{Ti}$ substrates. ${ }^{3,13}$ According to previous reports, $\mathrm{Mg}^{2+}$ supplements induce the osteoblast cells

Figure 6. (a) $\left[\mathrm{Mg}^{2+}\right]_{\mathrm{i}}$ and (b) $\left[\mathrm{Ca}^{2+}\right]_{\mathrm{i}}$ of osteoblasts cultured on l-HAAZ31, h-HA-AZ31, l-HA-Ti, h-HA-Ti and Ti substrates for 3, 7, and 14 days. Statistical analysis: Values are expressed as mean $\pm \mathrm{SD}$. One-way ANOVA with posthoc Tukey test with significance level of $* P<0.05$, $* * P<0.01$ indicate the comparison between 1 -/h-HA-AZ31 and l-/hHA-Ti substrates; \#P $<0.05$, \#\#P $<0.01$ indicate comparison of different samples (1-/h-HA-AZ31 and l-/h-HA-Ti substrates) vs Ti; $\Delta P$ $<0.05$ and $\Delta \Delta P<0.01$ indicate the pairwise comparison of samples.

proliferation and differentiation. ${ }^{16,30,31}$ In addition, reports demonstrated that h-HA stimulate the differentiation as compared to l-HA. ${ }^{9,10}$ However, these studies did not consider the properties of HA to be used for the functionalization of Ti. ${ }^{6,7,27}$ This is the first report evaluating the osteoblast cellular response to (a) 1/h-HA functionalized on $\mathrm{Ti}$ and corrosion resistant AZ31 substrate and (b) $\mathrm{Mg}^{2+}$ stimulated CCM of h/lHA-AZ31 substrates (produced due to the corrosion of AZ31 $\mathrm{Mg}$ alloy). Characterization of $1-/ \mathrm{h}-\mathrm{HA}$ coated AZ31-Mg and Ti alloys using AFM, contact angle measurements and quantifica- 
tion of hyaluronic acid confirmed the HA-functionalization on the silane coated AZ31 and Ti substrates.

Furthermore, osteoblasts response to 1/-h-HA coated AZ31 and $\mathrm{Ti}$ substrate was evaluated. In this study, we found that osteoblasts adhesion decreases on h-HA coated AZ31 and Ti alloy as compared to l-HA coated substrates. Previous reports showed that the resistance to cell adhesion on h-HA surfaces over l-HA is probably due to the greater repulsion effect of the negatively charged proteoglycan of the cell with the h-HA. ${ }^{27}$ Literature also showed that the wettability of surface affects the adhesion of the osteoblast cells. ${ }^{32}$ Therefore, an improved osteoblasts cell adhesion on l-HA over h-HA coated substrate can be also attributed to the relatively greater hydrophilicity of the former substrate. The cell shape of osteoblast was found to be flattened, extended and interconnected on HA coated substrates. However, osteoblasts adhered to bare AZ31 Mg alloy were circularly shaped and sparsely viable, which is likely due to its rapid degradation in HEPES DMEM.,19,21 Furthermore, cell adhesion and proliferation of osteoblasts on different substrates were determined in terms of increase in DNA concentration during the culture period. It was seen that cell adhesion density decreased on HA-coated AZ31 substrates as compared to the 1/ h-HA-coated or uncoated Ti substrates. A similar trend was observed in the proliferation of osteoblast monitored over a period of 14 days. The cell proliferation on 1-HA-AZ31/Ti was significantly increased when compared to h-HA-AZ31/Ti substrates. Kim et al. showed that in comparison to high molecular weight HA (i.e., $200 \mathrm{kDa})$, low molecular $(50 \mathrm{kDa})$ counterparts may provide favorable conditions for osteoblast proliferation. ${ }^{33}$ Likewise, Zhao et al. also demonstrated the higher osteo-proliferative activity on low-molecular-weight HA $(\leq 110 \mathrm{kDa})$ as compared to high-molecular-weight HA $(\leq 2500$ $\mathrm{kDa}) .{ }^{10}$ The findings of the present study are in agreement with those of the previous studies and suggest that osteoblasts can actively proliferate on low molecular weight HA functionalized $\mathrm{AZ31}$ and $\mathrm{Ti}$ substrates. However, the proliferation of osteoblasts on 1-/h-HA-AZ31 was decreased significantly when compared to l-/h-HA-Ti equivalents. This could be attributed to the biodegradable nature of the AZ31 substrate producing corrosion byproducts (evolution of $\mathrm{H}_{2}$ gas and $\mathrm{pH}$ change), thereby affecting cell viability and adhesion. In addition, functionalization of hyaluronic acid on biodegradable $\mathrm{Mg}$ alloy is not just to support the growth of the bone-related cells but also the degradable nature of $\mathrm{Mg}$ and its alloy is beneficial for orthopedic implant applications.

The effect of HA molecular weight functionalized on $\mathrm{Ti}$ and AZ31 substrates on the osteogenic differentiation of osteoblast cells was evaluated by ALP activity, expression of collagen and the formation of mineral nodules. Contrary to the trend of osteoblasts proliferation, h-HA-AZ31 and l-HA-AZ31 showed enhanced differentiation efficiency over l-HA-Ti and h-HA-Ti substrates respectively, whereas $\mathrm{Ti}$ substrate showed the least ALP activity. The results indicated that there are two factors stimulating the intracellular ALP activity (a) functionalization of the substrate with h-HA and (b) higher concentration of $\left[\mathrm{Mg}^{2+}\right]_{\mathrm{e}}$ in CCM of AZ31 substrates (Figure 7). Osteoblasts express ALP enzyme in the early stages of osteogenic differentiation, which participates in the mineralization of extracellular matrix (ECM). ${ }^{34}$ Previous studies showed that hHA enhanced the differentiation of osteoblasts by upregulating the ALP activity as compared to the $1-\mathrm{HA} .{ }^{10}$ In addition, it has been reported that $\left[\mathrm{Mg}^{2+}\right]_{\mathrm{e}}(5-10 \mathrm{mM})$ in CCM stimulate the intracellular ALP activity. ${ }^{17}$

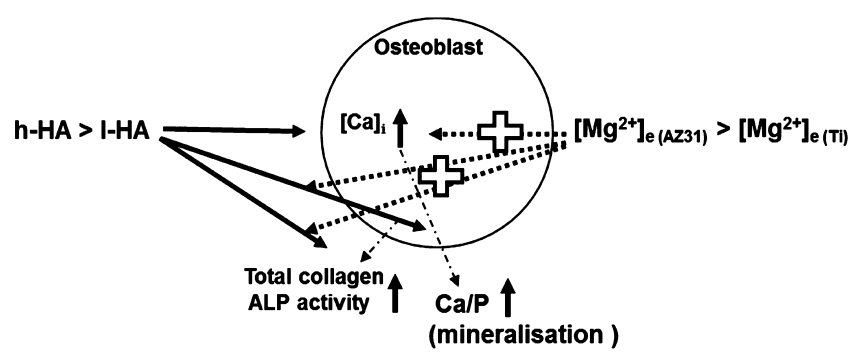

Figure 7. Effect of 1-HA, h-HA, and $\left[\mathrm{Mg}^{2+}\right]_{\mathrm{e}}$ on the differentiation markers of osteoblast cells. In comparison to 1-HA, h-HA enhanced $\left[\mathrm{Ca}^{2+}\right]_{\mathrm{i}}$ and other differentiation markers. The presence of $\left[\mathrm{Mg}^{2+}\right]_{\mathrm{e}(\mathrm{AZ} 31)}$ augmented the $\left[\mathrm{Ca}^{2+}\right]_{\mathrm{i}}$ and differentiation of osteoblasts.

Furthermore, the synthesis of collagen during osteogenic differentiation of osteoblasts on different substrates was evaluated by hydroxyproline assay. Collagen is the most abundant extracellular matrix synthesized by osteoblast cells and essential for ECM mineralization. ${ }^{26}$ Generally, synthesis of collagen increases throughout the culture period and is a strong indicator of osteoblasts differentiation. Osteoblasts cultured on h-HA-AZ31 and 1-HA-AZ31 showed significant higher collagen synthesis as compared to the h-HA-Ti and l-HA-Ti substrates respectively, whereas uncoated $\mathrm{Ti}$ substrate showed the lowest hydroxyproline content among other substrates. Previously Zhao and Lai et al. reported that in comparison to l-HA, cells in response to h-HA induced a greater expression of collagen. ${ }^{10,27}$ In addition, the $\mathrm{Mg}^{2+}$ ions conditioned CCM has also been reported to enhance the collagen synthesis. ${ }^{17,25}$ The presented results are in agreement with the previous studies, which indicated that h-HA and extracellular $\mathrm{Mg}^{2+}$ synergistically enhanced the differentiation of osteoblasts (Figure 7). In an ordered sequence of events observed during osteoblast differentiation, an increased ALP activity in the early stage is followed by the increased synthesis of collagen, which participates in the mineralization of ECM. ${ }^{25}$ The effect of the molecular weight of hyaluronic acid functionalized AZ31 and Ti substrates on the mineralization of ECM after 14 days of cell culture was evaluated by SEM-EDX analysis. It was observed that the deposition of $\mathrm{Ca}$ and $\mathrm{P}$ minerals were higher on $1 / \mathrm{h}-\mathrm{HA}-\mathrm{AZ} 31$ substrates as compared to l/h-HA-Ti substrate (Table 2 and Figure 7). The enhanced matrix mineralization activity of h-HA in the presence of extracellular $\mathrm{Mg}^{2+}$ (h-HA-AZ31 substrate) was accompanied by greater expression of intracellular ALP and collagen during various stages of the differentiation process (Figure 7). These results support the enhanced differentiation of osteoblast cells cultured on the h-HA-AZ31 substrate. Furthermore, various studies have been conducted to evaluate the effect of l/-h-HA concentration on osteoblasts differentiation. ${ }^{9,10,13}$ In this study, the grafting amount of 1-HA functionalized on AZ31 and Ti substrate is lesser than the h-HA counterpart. Since we have used an enzymatic method to quantify HA, it is expected to get a relatively higher grafted amount of high molecular weight HA due to long chain length when compared to the low-molecularweight HA surface. According to previously reported literature, a given level of osteoblasts differentiation induced by h-HA observed at a significantly lower concentration as compared to lHA. ${ }^{9,10,13}$ Interestingly these studies also demonstrated that improved osteoblasts functions induced by h-HA over l-HA have been maintained; even if the concentration for l-HA is at a higher level to that of h-HA. Thus, an improved osteoblast function in response to h-HA functionalized on AZ31 and Ti surface as compared to l-HA counterparts can be attributed to 
the effect of molecular weight instead of grafting levels of $1-/ \mathrm{h}$ HA. The above-mentioned differentiation results indicate that irrespective of the AZ31 or Ti metal substrate studied, h-HA significantly enhanced the differentiation of osteoblasts over 1HA. It is well-known that hyaluronic acid interacts with receptors expressed by bone-related cells, such as CD44 (cell membrane-tethered glycoprotein) and RHAMM (receptor for HA-mediated motility), which are expressed by osteoblast lineage cells. ${ }^{35}$ Hyaluronic acid is a principal ligand for the CD44 receptor. ${ }^{8}$ Previous studies reported that h-HA can enhance the differentiation markers of the osteoblast cells through the stimulation of CD $44^{13}$. Similarly, Chen et al, demonstrated the reduced mineralization of CD44 knocked out dental pulp cells in response to h-HA, thereby emphasizing the role of the CD44 receptor in the differentiation of osteoblasts. ${ }^{8}$ Another study reported that a number of CD44 receptor binding sites are proportional to the molecular weight of hyaluronic acid, thereby increasing CD44 receptor density, and more differentiation can be achieved. RHAMM is another prominent receptor that could make up the loss of CD $44 . .^{13}$ Therefore, the enhanced differentiation activity of h-HA functionalized surface as compared low molecular weight counterpart can be attributed to the CD44-related cell signaling. The results also showed that osteoblasts cultured on 1/h-HA AZ31 substrates further enhanced the HA-induced differentiation. Generally, Mgbased alloys in the chloride-rich aqueous environment can rapidly degrade to release $\mathrm{Mg}^{2+}$ ions, thereby increasing the solution alkalinity inducing toxicity in the surrounding cell/ tissues. ${ }^{1}$ Therefore, it is important to control the degradation of $\mathrm{Mg}$ alloys under physiological conditions for potential biodegradable orthopedic implants.

Many reports demonstrated enhanced differentiation of osteoblasts cultured in $\mathrm{Mg}^{2+}$ ions conditioned CCM with alkaline $\mathrm{pH}(7.6-8.5) .{ }^{25,34}$ In this study, we determined the $\mathrm{pH}$ and $\mathrm{Mg}^{2+}$ released in DMEM from 1/h-HA coated-AZ31 and 1-/ h-HA coated-Ti substrates seeded with and without osteoblasts for 3,7 , and 14 days. It was observed that $\left[\mathrm{Mg}^{2+}\right]_{\mathrm{e}}$ for all of the AZ3-based substrates decreased steadily at each of the time points, however, the concentration was still higher than CCM of Ti-based substrates and CCM alone. The decreasing release rate of $\mathrm{Mg}^{2+}$ ions with the incubation time can be attributed to $\mathrm{Mg}$ alloy forming a protective surface passivation layer. ${ }^{37}$ Interestingly, the immersion medium of 1/h-HA-AZ31 seeded with osteoblasts showed a significant decrease in $\left[\mathrm{Mg}^{2+}\right]_{\mathrm{e}}$ when compared to AZ31-HA substrate without cells at each time point. Similarly, the $\mathrm{pH}$ decreased significantly for l/h-HA-AZ31 substrates with osteoblasts as compared AZ31-HA substrate without osteoblasts. These results indicate that the corrosion of 1/h-HA-AZ31 with osteoblasts reduced significantly as compared to the counterpart without cells. There are few explanations for such enhanced corrosion protection of $1 / \mathrm{h}$ HA-AZ31 (with osteoblasts). First, the monolayer of osteoblasts can act as a corrosion protection layer by depositing $\mathrm{Ca}-\mathrm{P}$ minerals on the surface through the process of ECM mineralization and/or formation of passivation layer due to the degradation of the AZ31-Mg alloy as observed from EDX elemental analysis. ${ }^{3,38,39}$ Second, osteoblasts use $\mathrm{Mg}^{2+}$ for various metabolic activities. Previous studies demonstrated the influence of living cells in preventing the degradation of $\mathrm{Mg}$ alloy through the enhanced metabolic activity of cells (reducing the $\mathrm{pH}$ of the medium) and deposition of corrosion products on the surface. $^{38,39}$ These previous studies conducted experiments in nonosteogenic medium condition, whereas the present study showed the influence of ECM mineralization on the corrosion protection of AZ31 Mg alloy in the differentiation CCM. It has been pointed that moderate $\left[\mathrm{Mg}^{2+}\right]_{\mathrm{e}}$ can be tolerated by bonerelated cells and give rise to the higher expression of differentiation markers. ${ }^{17,30}$ However, excessive release of $\mathrm{Mg}^{2+}$ ions resulting from rapid degradation of $\mathrm{Mg}$ alloy is a concern and can cause cell damage jeopardizing the bone healing process. ${ }^{4,40,41}$ Regarding $\mathrm{pH}$ values, it has been reported that the differentiation of osteoblasts significantly enhances with the $\mathrm{pH}$ increase up to $8.5 .^{25,36}$ Previous work described that the excessive corrosion of AZ31 Mg alloy lead to the alkalization of $\mathrm{CCM}$ and can cause the $\mathrm{pH}$ to increase above 9.0, which is detrimental to cell adhesion, proliferation and differentiation. ${ }^{4,40,41}$ The results presented in this study showed the controlled degradation of $\mathrm{Mg}$ alloy, which provided favorable conditions such as appropriate $\mathrm{pH}(<8.5)$ and optimum $\left[\mathrm{Mg}^{2+}\right]_{\mathrm{e}}$ for enhanced osteoblast differentiation when compared to the Ti-based samples.

To understand the effect of 1-/h-HA and/or $\left[\mathrm{Mg}^{2+}\right]_{\mathrm{e}}$ on the mineralization of osteoblasts, we determined the $\left[\mathrm{Mg}^{2+}\right]_{\mathrm{i}}$ and $\left[\mathrm{Ca}^{2+}\right]_{\mathrm{i}}$ of osteoblasts at different time periods. The results showed that h-HA significantly stimulate $\left[\mathrm{Ca}^{2+}\right]_{\mathrm{i}}$ as compared to 1-HA samples during 14 days of cell culture (Figure 7). Previous studies reported that increased CD44 receptor density on h-HA illicit greater mineralization of osteoblasts. ${ }^{10,13}$ In addition, Boonrungsiman et al. explained not only the genesis and role of intracellular $\mathrm{Ca}^{2+}$ in propagating the nucleation of mineralized nodules within the ECM but also identified higher $\left[\mathrm{Ca}^{2+}\right]_{\mathrm{i}}$ during osteogenic differentiation of osteoblast cells. ${ }^{42}$ Therefore, in comparison to l-HA coated surfaces, enhanced differentiation of osteoblasts in response to h-HA can be attributed to increased CD44 receptor density on h-HA-coated $\mathrm{Ti} / \mathrm{AZ31}$ substrates. The influence of $\left[\mathrm{Mg}^{2+}\right]_{\mathrm{e}}$ on osteogenic differentiation of osteoblast by regulating $\left[\mathrm{Mg}^{2+}\right]_{\mathrm{i}}$, and $\left[\mathrm{Ca}^{2+}\right]_{\mathrm{i}}$ has been explained by previous studies. ${ }^{16,25,29}$ However, reports showed different $\left[\mathrm{Mg}^{2+}\right]_{\mathrm{e}}$ improving the differentiation of osteoblast ranging from $<1$ to $10 \mathrm{mM} .^{16,17}$ In this study, we found that decreasing $\left[\mathrm{Mg}^{2+}\right]_{\mathrm{e}}(\sim 12 \mathrm{mM}$ (day 3$)$ to $5 \mathrm{mM}$ (day 14)) throughout the culture period also match this trend for $\left[\mathrm{Mg}^{2+}\right]_{\mathrm{i}}$, but reveal contrary trend for $\left[\mathrm{Ca}^{2+}\right]_{\mathrm{i}}$. This indicates that (a) $\left[\mathrm{Ca}^{2+}\right]_{\mathrm{i}}$ is regulated by $\left[\mathrm{Mg}^{2+}\right]_{\mathrm{e}}$ and (b) lower $\left[\mathrm{Mg}^{2+}\right]_{\mathrm{i}}$ stimulates the $\left[\mathrm{Ca}^{2+}\right]_{\mathrm{i}}$. This also showed that at an optimum concentration of $\left[\mathrm{Mg}^{2+}\right]_{\mathrm{e}}$ ions enhanced the differentiation of osteoblasts as observed in the case of AZ31 substrates (Figures 5 and 6). Our findings are in agreement with the previous studies which reported the $\left[\mathrm{Mg}^{2+}\right]_{\mathrm{e}}$ dependent increase of $\left[\mathrm{Mg}^{2+}\right]_{\mathrm{i}}$ and $\left[\mathrm{Ca}^{2+}\right]_{\mathrm{i} .}{ }^{16,25,29}$ Deficient $\left[\mathrm{Mg}^{2+}\right]_{\mathrm{i}}$ was reported to reduce the osteoblastic activity and impair bone remodelling. ${ }^{18}$ However, overdose $\left[\mathrm{Mg}^{2+}\right]_{\mathrm{i}}$ is detrimental to the viability of cells and retarding the ECM mineralization of bone-related cells. ${ }^{16,43}$ Therefore, an enhanced mineralization showed by the h-HAAZ31 substrate can be attributed to the $\mathrm{Mg}^{2+}$ released from the AZ31 substrate and positive effects of h-HA.

\section{CONCLUSION}

This study illustrated the proliferation and differentiation of osteoblast cells in response to the hyaluronic acid of different molecular weight immobilized on silane coated AZ31 Mg and Ti alloy substrates. The proliferation of osteoblasts on l-HA-coated AZ31/Ti substrates significantly enhanced as compared to the h-HA counterpart. However, the overall proliferation of osteoblasts was significantly low on HA-coated (low- and high-molecular-weight HA) AZ31 Mg substrates when 
compared to HA-coated Ti substrates, which is attributed to the corrosion of AZ31 Mg alloy in the culture medium. On the contrary, osteogenic differentiation was enhanced in response to h-HA over l-HA modified AZ31 and Ti substrates. The steady decrease of extracellular $\mathrm{Mg}^{2+}$ over 14 days regulated the concomitant increase in $\left[\mathrm{Ca}^{2+}\right]_{\mathrm{i}}$ with the corresponding decrease in $\left[\mathrm{Mg}^{2+}\right]_{\mathrm{i}}$, however, the latter showed a significant increase for HA-coated AZ31 substrates (h-HA-AZ31 and l-HAAZ31) when compared to the Ti-based substrates (h-HA-Ti, lHA-Ti and uncoated Ti). Particularly, h-HA coated AZ31 substrates (h-HA-AZ31) greatly enhanced the osteoblasts differentiation and mineralization of ECM, which can be ascribed to the osteoinductive activity of h-HA, alkaline cell culture medium as well as upregulated $\left[\mathrm{Ca}^{2+}\right]_{\mathrm{i}}$. These findings are critical to understanding the role of hyaluronic acid molecular weight functionalized on different metal substrates affecting bone healing.

\section{ASSOCIATED CONTENT}

\section{S Supporting Information}

The Supporting Information is available free of charge on the ACS Publications website at DOI: 10.1021/acsbiomaterials.8b00968.

Additional data on the quantification of hydroxyproline content (not-normalized to DNA content), quantification of $\mathrm{Mg}^{2+}$ in the cell culture medium, and AFM images for different substrates (PDF)

\section{AUTHOR INFORMATION}

\section{Corresponding Author}

*E-mail: swarna.jaiswal@dit.ie or swarna.jaiswal@outlook.com. ORCID $\odot$

Swarna Jaiswal: 0000-0003-1414-9052

Notes

The authors declare no competing financial interest.

\section{ACKNOWLEDGMENTS}

The authors acknowledge the financial support to conduct this study through DIT, Fiosraigh Scholarship Programme 2014.

\section{REFERENCES}

(1) Agarwal, S.; Curtin, J.; Duffy, B.; Jaiswal, S. Biodegradable Magnesium Alloys for Orthopaedic Applications: A Review on Corrosion, Biocompatibility and Surface Modifications. Mater. Sci. Eng., C 2016, 68, 948-963.

(2) Shalabi, M. M.; Wolke, J. G. C.; Cuijpers, V. M. J. I.; Jansen, J. a. Evaluation of Bone Response to Titanium-Coated Polymethyl Methacrylate Resin (PMMA) Implants by X-Ray Tomography. J. Mater. Sci.: Mater. Med. 2007, 18, 2033-2039.

(3) Agarwal, S.; Morshed, M.; Labour, M.-N.; Hoey, D.; Duffy, B.; Curtin, J.; Jaiswal, S. Enhanced Corrosion Protection and Biocompatibility of a PLGA-silane Coating on AZ31 Mg Alloy for Orthopaedic Applications. RSC Adv. 2016, 6 (115), 113871-113883.

(4) Walker, J.; Shadanbaz, S.; Kirkland, N. T.; Stace, E.; Woodfield, T.; Staiger, M. P.; Dias, G. J. Magnesium Alloys: Predicting in Vivo Corrosion with in Vitro Immersion Testing. J. Biomed. Mater. Res., Part B 2012, 100, 1134-1141.

(5) Chua, P. H.; Neoh, K. G.; Kang, E. T.; Wang, W. Surface Functionalization of Titanium with Hyaluronic Acid/chitosan Polyelectrolyte Multilayers and RGD for Promoting Osteoblast Functions and Inhibiting Bacterial Adhesion. Biomaterials 2008, 29 (10), 1412-1421.
(6) Hu, X.; Neoh, K. G.; Shi, Z.; Kang, E. T.; Poh, C.; Wang, W. An in Vitro Assessment of Titanium Functionalized with Polysaccharides Conjugated with Vascular Endothelial Growth Factor for Enhanced Osseointegration and Inhibition of Bacterial Adhesion. Biomaterials 2010, 31 (34), 8854-8863.

(7) Zhang, X.; Li, Z.; Yuan, X.; Cui, Z.; Yang, X. Fabrication of Dopamine-Modified Hyaluronic Acid/chitosan Multilayers on Titanium Alloy by Layer-by-Layer Self-Assembly for Promoting Osteoblast Growth. Appl. Surf. Sci. 2013, 284, 732-737.

(8) Chen, K. L.; Yeh, Y. Y.; Lung, J.; Yang, Y. C.; Yuan, K. Mineralization Effect of Hyaluronan on Dental Pulp Cells via CD44. J. Endod 2016, 42 (5), 711-716.

(9) Huang, L.; Cheng, Y. Y.; Koo, P. L.; Lee, K. M.; Qin, L.; Cheng, J. C. Y.; Kumta, S. M. The Effect of Hyaluronan on Osteoblast Proliferation and Differentiation in Rat Calvarial-Derived Cell Cultures. J. Biomed. Mater. Res. 2003, 66, 880-884.

(10) Zhao, N.; Wang, X.; Qin, L.; Guo, Z.; Li, D. Effect of Molecular Weight and Concentration of Hyaluronan on Cell Proliferation and Osteogenic Differentiation in Vitro. Biochem. Biophys. Res. Commun. 2015, 465 (3), 569-574.

(11) Toole, B. P. Hyaluronan: From Extracellular Glue to Pericellular Cue. Nat. Rev. Cancer 2004, 4 (7), 528-539.

(12) Noble, P. W. Hyaluronan and Its Catabolic Products in Tissue Injury and Repair. Matrix Biol. 2002, 21 (1), 25-29.

(13) Yang, C.; Cao, M.; Liu, H.; He, Y.; Xu, J.; Du, Y.; Liu, Y.; Wang, W.; Cui, L.; Hu, J.; et al. The High and Low Molecular Weight Forms of Hyaluronan Have Distinct Effects on CD44 Clustering. J. Biol. Chem. 2012, 287 (51), 43094-43107.

(14) Kothapalli, D.; Zhao, L.; Hawthorne, E. A.; Cheng, Y.; Lee, E.; Puré, E.; Assoian, R. K. Hyaluronan and CD44 Antagonize MitogenDependent Cyclin D1 Expression in Mesenchymal Cells. J. Cell Biol. 2007, 176 (4), 535-544.

(15) Umemura, N.; Ohkoshi, E.; Tajima, M.; Kikuchi, H.; Katayama, T.; Sakagami, H. Hyaluronan Induces Odontoblastic Differentiation of Dental Pulp Stem Cells via CD44. Stem Cell Res. Ther. 2016, 7 (1), 112.

(16) Zhang, L.; Yang, C.; Li, J.; Zhu, Y.; Zhang, X. High Extracellular Magnesium Inhibits Mineralized Matrix Deposition and Modulates Intracellular Calcium Signaling in Human Bone Marrow-Derived Mesenchymal Stem Cells. Biochem. Biophys. Res. Commun. 2014, 450 (4), 1390-1395.

(17) Yoshizawa, S.; Brown, A.; Barchowsky, A.; Sfeir, C. Magnesium Ion Stimulation of Bone Marrow Stromal Cells Enhances Osteogenic Activity, Simulating the Effect of Magnesium Alloy Degradation. Acta Biomater. 2014, 10 (6), 2834-2842.

(18) Leidi, M.; Dellera, F.; Mariotti, M.; Maier, J. A. M. High Magnesium Inhibits Human Osteoblast Differentiation in Vitro. Magnes Res. 2011, 24 (1), 1-6.

(19) Kunjukunju, S.; Roy, A.; Ramanathan, M.; Lee, B.; Candiello, J. E.; Kumta, P. N. A Layer-by-Layer Approach to Natural PolymerDerived Bioactive Coatings on Magnesium Alloys. Acta Biomater. 2013, 9 (10), 8690-8703.

(20) Liu, X.; Yue, Z.; Romeo, T.; Weber, J.; Scheuermann, T.; Moulton, S.; Wallace, G. Biofunctionalized Anti-Corrosive Silane Coatings for Magnesium Alloys. Acta Biomater. 2013, 9 (10), 86718677.

(21) Agarwal, S.; Riffault, M.; Hoey, D.; Duffy, B.; Curtin, J.; Jaiswal, S. Biomimetic Hyaluronic Acid-Lysozyme Composite Coating on AZ31 $\mathrm{Mg}$ Alloy with Combined Antibacterial and Osteoinductive Activities. ACS Biomater. Sci. Eng. 2017, 3 (12), 3244-3253.

(22) D’Sa, R. a.; Dickinson, P. J.; Raj, J.; Pierscionek, B. K.; Meenan, B. J. Inhibition of Lens Epithelial Cell Growth via Immobilisation of Hyaluronic Acid on Atmospheric Pressure Plasma Modified Polystyrene. Soft Matter 2011, 7 (2), 608-617.

(23) Takahashi, T.; Ikegami-Kawai, M.; Okuda, R.; Suzuki, K. A Fluorimetric Morgan-Elson Assay Method for Hyaluronidase Activity. Anal. Biochem. 2003, 322, 257-263.

(24) Chou, D. T.; Hong, D.; Saha, P.; Ferrero, J.; Lee, B.; Tan, Z.; Dong, Z.; Kumta, P. N. In Vitro and in Vivo Corrosion, 
Cytocompatibility and Mechanical Properties of Biodegradable Mg-YCa-Zr Alloys as Implant Materials. Acta Biomater. 2013, 9 (10), 85188533.

(25) Li, B.; Han, Y.; Li, M. Enhanced Osteoblast Differentiation and Osseointegration of a Bio-Inspired HA Nanorod Patterned Pore-Sealed $\mathrm{MgO}$ Bilayer Coating on Magnesium. J. Mater. Chem. B 2016, 4 (4), 683-693.

(26) Pandey, M.; Kapila, R.; Kapila, S. Osteoanabolic Activity of Whey-Derived Anti-Oxidative (MHIRL and YVEEL) and AngiotensinConverting Enzyme Inhibitory (YLLF, ALPMHIR, IPA and WLAHK) Bioactive Peptides. Peptides 2018, 99, 1-7.

(27) Lai, J. Y.; Tu, I. H. Adhesion, Phenotypic Expression, and Biosynthetic Capacity of Corneal Keratocytes on Surfaces Coated with Hyaluronic Acid of Different Molecular Weights. Acta Biomater. 2012, 8 (3), 1068-1079.

(28) Córdoba, L. C.; Marques, A.; Taryba, M.; Coradin, T.; Montemor, F. Hybrid Coatings with Collagen and Chitosan for Improved Bioactivity of Mg Alloys. Surf. Coat. Technol. 2018, 341, 103113.

(29) Chen, W. Y. J. Functions of Hyaluronan in Wound Repair; Woodhead Publishing, 2002. DOI: 10.1533/9781845693121.147

(30) He, L. Y.; Zhang, X. M.; Liu, B.; Tian, Y.; Ma, W. H. Effect of Magnesium Ion on Human Osteoblast Activity. Braz. J. Med. Biol. Res. 2016, 49 (7), 1-6.

(31) Lorenz, C.; Brunner, J. G.; Kollmannsberger, P.; Jaafar, L.; Fabry, B.; Virtanen, S. Effect of Surface Pre-Treatments on Biocompatibility of Magnesium. Acta Biomater. 2009, 5 (7), 2783-2789.

(32) Wei, J.; Igarashi, T.; Okumori, N.; Igarashi, T.; Maetani, T.; Liu, B.; Yoshinari, M. Influence of Surface Wettability on Competitive Protein Adsorption and Initial Attachment of Osteoblasts. Biomed. Mater. 2009, 4 (4), 045002.

(33) Kim, J.; Park, Y.; Tae, G.; Kyu, B. L.; Chang, M. H.; Soon, J. H.; In, S. K.; Noh, I.; Sun, K. Characterization of Low-Molecular-Weight Hyaluronic Acid-Based Hydrogel and Differential Stem Cell Responses in the Hydrogel Microenvironments. J. Biomed. Mater. Res., Part A 2009, 88 (4), 967-975.

(34) Tsigkou, O.; Jones, J. R.; Polak, J. M.; Stevens, M. M. Differentiation of Fetal Osteoblasts and Formation of Mineralized Bone Nodules by $45 S 5$ Bioglass ${ }^{\circledR}$ conditioned Medium in the Absence of Osteogenic Supplements. Biomaterials 2009, 30 (21), 3542-3550.

(35) Nedvetzki, S.; Gonen, E.; Assayag, N.; Reich, R.; Williams, R. O.; Thurmond, R. L.; Huang, J.-F.; Neudecker, B. A.; Wang, F.-S.; Turley, E. A.; et al. RHAMM, a Receptor for Hyaluronan-Mediated Motility, Compensates for CD44 in Inflamed CD44-Knockout Mice: A Different Interpretation of Redundancy. Proc. Natl. Acad. Sci. U. S. A. 2004, 101 (52), 18081-18086.

(36) Dixit, C. K.; Mcdonagh, C.; Maccraith, B. D.; Biophotonics, N.; Platform, I. Surface Modification and Conjugation Strategies for Bioassay/Biomaterial Applications. PhD Thesis, Dublin City University, Dublin, Ireland, November 2011. http://doras.dcu.ie/17151/1/ Thesis_Chandra_Dixit_26-07-2012_r.pdf.

(37) Ostrowski, N.; Lee, B.; Enick, N.; Carlson, B.; Kunjukunju, S.; Roy, A.; Kumta, P. N. Corrosion Protection and Improved Cytocompatibility of Biodegradable Polymeric Layer-by-Layer Coatings on AZ31 Magnesium Alloys. Acta Biomater. 2013, 9 (10), 87048713.

(38) Kannan, M. B.; Yamamoto, A.; Khakbaz, H. Influence of Living Cells (L929) on the Biodegradation of Magnesium-Calcium Alloy. Colloids Surf., B 2015, 126, 603-606.

(39) Witecka, A.; Yamamoto, A.; Swięszkowski, W. Influence of SaOS2 Cells on Corrosion Behavior of Cast Mg-2.0Zn0.98Mn Magnesium Alloy. Colloids Surf., B 2017, 150, 288-296.

(40) Gu, X.; Zheng, Y.; Cheng, Y.; Zhong, S.; Xi, T. In Vitro Corrosion and Biocompatibility of Binary Magnesium Alloys. Biomaterials 2009, 30 (4), 484-498.

(41) Wong, H. M.; Yeung, K. W. K.; Lam, K. O.; Tam, V.; Chu, P. K.; Luk, K. D. K.; Cheung, K. M. C. A Biodegradable Polymer-Based Coating to Control the Performance of Magnesium Alloy Orthopaedic Implants. Biomaterials 2010, 31 (8), 2084-2096.
(42) Boonrungsiman, S. The Role of Intracellular Calcium Phosphate in Osteoblast-Mediated Bone Apatite Formation. Proc. Natl. Acad. Sci. U. S. A. 2012, 109 (35), 14170-14175.

(43) Zhao, D.; Witte, F.; Lu, F.; Wang, J.; Li, J.; Qin, L. Current Status on Clinical Applications of Magnesium-Based Orthopaedic Implants: A Review from Clinical Translational Perspective. Biomaterials 2017, 112, 287-302. 